\title{
Projected effects of tobacco smoking on worldwide tuberculosis control: mathematical modelling analysis
}

\author{
() $(\Theta)$ OPEN ACCESS
}

\author{
Sanjay Basu physician ${ }^{123}$, David Stuckler university lecturer in sociology ${ }^{34}$, Asaf Bitton instructor \\ in medicine ${ }^{56}$, Stanton A Glantz professor of medicine ${ }^{1}$
}

'Department of Medicine, University of California San Francisco, San Francisco, CA 94143, USA; ${ }^{2}$ Division of General Internal Medicine, San Francisco General Hospital, San Francisco; ${ }^{3}$ Department of Public Health and Policy, London School of Hygiene and Tropical Medicine, London, UK; ${ }^{4}$ Department of Sociology, Cambridge University, Cambridge, UK; ${ }^{5}$ Department of Health Care Policy, Harvard Medical School, Boston, MA, USA; ${ }^{6}$ Division of General Medicine, Brigham and Women's Hospital, Boston

\begin{abstract}
Objectives Almost $20 \%$ of people smoke tobacco worldwide-a percentage projected to rise in many poor countries. Smoking has been linked to increased individual risk of tuberculosis infection and mortality, but it remains unclear how these risks affect population-wide tuberculosis rates.

Design We constructed a state transition, compartmental, mathematical model of tuberculosis epidemics to estimate the impact of alternative future smoking trends on tuberculosis control. We projected tuberculosis incidence, prevalence, and mortality in each World Health Organization region from 2010 to 2050, and incorporated changing trends in smoking, case detection, treatment success, and HIV prevalence.

Results The model predicted that smoking would produce an excess of 18 million tuberculosis cases (standard error 16-20) and 40 million deaths from tuberculosis (39-41) between 2010 and 2050, if smoking trends continued along current trajectories. The effect of smoking was anticipated to increase the number of tuberculosis cases by $7 \%$ (274 million $v 256$ million) and deaths by $66 \%$ (101 million $v 61$ million), compared with model predictions that did not account for smoking. Smoking was also expected to delay the millennium development goal target to reduce tuberculosis mortality by half from 1990 to 2015 . The model estimated that aggressive tobacco control (achieving a 1\% decrease in smoking prevalence per year down to eradication) would avert 27 million smoking attributable deaths from tuberculosis by 2050 . However, if the prevalence of smoking increased to $50 \%$ of adults (as observed in countries with high tobacco use), the model estimated that 34 million additional deaths from tuberculosis would occur by 2050
\end{abstract}

Conclusions Tobacco smoking could substantially increase tuberculosis cases and deaths worldwide in coming years, undermining progress towards tuberculosis mortality targets. Aggressive tobacco control could avert millions of deaths from tuberculosis.

\section{Introduction}

Global health experts set a millennium development goal to reduce tuberculosis prevalence and mortality by half between 1990 and $2015 .^{12}$ To achieve this target, programmes of tuberculosis control have focused on detecting and treating active tuberculosis cases to reduce their infectiousness, breaking the transmission chain. ${ }^{3}$ Several countries with a high burden of tuberculosis, however, are unlikely to meet the millennium development goal targets despite high levels of detection and treatment, leading the World Health Organization to question whether key risk factors for infection must also be addressed. ${ }^{345}$

Tobacco smoking is a prevalent risk factor for tuberculosis. Nearly a fifth of the world's population smokes tobacco or uses other tobacco products. ${ }^{6}$ Most cigarettes are smoked in countries with a high prevalence of tuberculosis, where multinational tobacco companies have expanded their markets. ${ }^{78}$ Recent reviews show weak infrastructure to regulate tobacco use and increasing smoking in the areas with endemic tuberculosis. ${ }^{69}$ Smoking increases the risk of latent tuberculosis by a factor of 1.9 (95\% confidence intervals 1.6 to 2.3 ), active tuberculosis by 2.0 ( 1.5 to 2.6 ), and death from tuberculosis by 2.6 ( 1.8 to 3.6), after adjusting for socioeconomic status (table $1 \Downarrow$ ). ${ }^{10}$ These moderate increases in individual risk of tuberculosis due to smoking might translate into a large impact at the population level, owing to the high prevalence of smoking. In India, for example, $38 \%$ of deaths from tuberculosis among middle aged men are attributed to smoking, ${ }^{18}$ costing India's economy three times its tuberculosis budget. ${ }^{19}$

Recent studies have used the population attributable risk of infection ${ }^{20}$ to calculate the potential impact of smoking on tuberculosis, linearly extrapolating the magnitude of increased 
tuberculosis cases and deaths as a result of individual increases in relative risk. ${ }^{1018}$ Because tuberculosis is an infectious disease, however, an increase in cases can result in the further increase of additional new cases at an exponential rather than linear rate, but only up to levels of saturation based on the degree of risky contact among infected and uninfected individuals in a

population. ${ }^{21}$ Furthermore, tuberculosis is a long course disease, and many individuals relapse or are not cured completely, with varying levels of protection from new active disease based on immunity from previous infection as well as chemoprophylaxis given to people with latent infections. ${ }^{22}$ Finally, when a risk factor not only increases the risk of primary infection but also increases the risk of mortality, it remains unclear how future prevalence will change, because the rise in mortality could outweigh the increase in incidence (Little's law:

prevalence=incidencexduration of disease, where duration of disease is reduced by higher mortality), producing non-intuitive changes to the dynamics of epidemics as well as the timing and effects of ongoing control measures. ${ }^{21}$

Mathematically modelling a population allows us to view how disease pathogenesis and the process of infection, progression, and mortality can change while the parameters that affect multiple points of disease infection and control are modified. So far, mathematical models of tuberculosis have accounted for HIV, new tuberculosis detection technologies, and drug resistance, ${ }^{23}{ }^{24}$ but not smoking. Our analysis aimed to provide an estimate of the impact of smoking and different scenarios for control of smoking on future trajectories of tuberculosis. We developed a state transition, compartmental, mathematical model of tuberculosis epidemics to estimate the effect of smoking on tuberculosis.

\section{Methods}

\section{Structure of mathematical model}

The model (fig $1 \Downarrow$ ) consisted of differential equations that described tuberculosis infection, pathogenesis, and mortality among populations older than 15 years (web appendix). It incorporated transition states representing susceptibility to tuberculosis infection, latent tuberculosis infection, and active tuberculosis disease. We derived natural history parameters describing the pathogenesis of tuberculosis in the model from studies of populations before widespread tobacco use, to avoid confounding our modifications that accounted for smoking (table 1).

The model incorporated smoking by estimating the population in each WHO region that actively smokes tobacco each year, to calculate the number of tuberculosis infections and deaths among smokers as well as the number of secondary infections and deaths resulting from each new case of smoking attributable tuberculosis. The model also included increased rates of non-tuberculosis mortality among smokers (for example, from cardiovascular disease). Therefore, we could see the effect of tobacco control on deaths from tuberculosis alone, since smoking related deaths not related to tuberculosis were tabulated separately.

We selected the model by comparing it with two previously published models ${ }^{25}{ }^{26}$ and using Akaike's information criterion to determine which model best fit available data using the fewest number of parameters (maximising accuracy while minimising uncertainty). ${ }^{27}$ The model in fig 1 produced a significantly better selection score than the two alternatives (difference in Akaike's information criterion scores $>10)^{28}$ when fit to annual tuberculosis incidence, prevalence, and mortality rates in 1990-2009 from each WHO region (web appendix) ${ }^{29} \mathrm{We}$ organised our simulations by WHO region for comparison with previous WHO analyses, ${ }^{12}$ although the model equations could apply to any population (web appendix).

\section{Modelling approach and underlying assumptions}

The model projects future tuberculosis cases and deaths from 2010 to 2050, incorporating birth and non-tuberculosis mortality rates specific to each WHO region. ${ }^{13}$ It also included rates of tuberculosis case detection and treatment success to simulate standard international protocols, ${ }^{29}$ since these factors reduce the duration of infectiousness and risk of mortality in tuberculosis. To project future expected rates of case detection and treatment success rates, we fit saturating exponential functions to annual tuberculosis case detection and treatment success data from 1994 to 2008 for each region, ${ }^{29}$ projecting future rates toward asymptotes of $80 \%$ case detection and $90 \%$ treatment success based on previous WHO analyses. ${ }^{30}$

We also used the model to estimate HIV prevalence trends and calculate how tuberculosis disease and mortality rates would increase among HIV infected people. We simulated annual HIV prevalence by fitting double logistic curves to adult HIV prevalence data from 1990 to $2010 .^{31}$

The model estimated smoking prevalence from data on tobacco demand ${ }^{32}$ (tonnes of tobacco sold per capita annually since 1970) by calculating the ratio between smoking prevalence and demand in 1991, the only year when both regional smoking prevalence and tobacco demand data were available. ${ }^{33}$ We then multiplied each region's annual tobacco demand by this prevalence-to-demand ratio to estimate the annual smoking prevalence, which we corrected for population age and sex distributions. ${ }^{13}$ To establish face validity of these smoking prevalence estimates, we verified that the projections were within 5\% of WHO's point prevalence smoking surveys available intermittently between 1990 and $2009 .{ }^{33}$ We assigned former smokers the same tuberculosis risks as never smokers, consistent with recent analyses of tuberculosis natural history. ${ }^{34}$ We constructed three scenarios for possible future smoking trends. The baseline scenario assumed that smoking rates in each region would continue changing at the same annual rate as from 2005 to 2010 up to a maximum of $40 \%$ (the maximum in any overall WHO region so $\mathrm{far}^{35}$ ). The pessimistic scenario assumed that smoking prevalence rates would rise by $0.72 \%$ per year, twice the global average rate in 2005-10, reaching a maximum of $50 \%$ prevalence (the highest rate observed in any individual country among people older than 15 years ${ }^{35}$ ). The optimistic scenario assumed that smoking prevalence would follow the baseline simulation until 2015 , and then fall by $1 \%$ per year (the rate of decline observed among US states with aggressive tobacco control programmes ${ }^{36}$ and a new goal in some nations ${ }^{37}$ ) until reaching $0 \%$.

\section{Sensitivity and uncertainty analyses}

We used two approaches for the sensitivity analysis. Firstly, we added the effect of passive smoking to the baseline model. Passive smoking is thought to increase the relative risk of tuberculosis infection (but not mortality) by a magnitude similar to that among active smokers. ${ }^{10}{ }^{38} \mathrm{We}$ assumed that passive smoking increased the effective smoke exposed population by $40 \%$ (95\% confidence intervals $10 \%$ to $60 \%$ ), based on an aggregate estimate among low income and middle income countries. ${ }^{35}$

Secondly, HIV and smoking might have a synergistic impact, such that HIV positive smokers die more rapidly than if they 
were only affected by either HIV or smoking alone. We simulated a scenario in which people affected by both HIV and smoking would lose an extra seven months of life because of the possible synergy (beyond the mortality effects of HIV and smoking individually), based on limited cohort data available so far. $^{39} 40$

We used Monte Carlo simulations to estimate the uncertainty in all of our simulations by sampling from the probability distributions of the input parameters. We reported the mean and standard error from 10000 simulations.

\section{Results}

\section{Baseline scenario}

The model estimated that smoking would cause 18 million excess cases of tuberculosis (standard error 16-20) between 2010 and 2050. The model projected a total of 256 million tuberculosis cases if it did not account for smoking (when the model was run with $0 \%$ smoking prevalence for all years), and 274 million cases if it included smoking. The model also estimated that smoking would cause 40 million excess deaths from tuberculosis (39 to 41) from 2010 to 2050 (61 million without smoking impact $v 101$ million deaths with smoking impact). Increases in tuberculosis incidence ranged from 5\% (in the western Pacific region) to $42 \%$ (in the eastern Mediterranean) (fig $2 \Downarrow$ ), and tuberculosis mortality increases ranged from $64 \%$ (in Europe) to $135 \%$ (in the eastern Mediterranean), when comparing the model ignoring smoking with the simulation incorporating current smoking trends (fig $3 \Downarrow$ ). The model estimated that the Americas, eastern Mediterranean, South IEast Asian, and western Pacific regions would miss the mortality millennium development goal because of smoking.

Smoking reduces the point prevalence of active tuberculosis by increasing tuberculosis mortality rates (fig $4 \Downarrow$ ). This reduced tuberculosis prevalence does not reflect improved control, but rather a higher number of deaths than new cases. Despite the slightly lower number of active tuberculosis cases that can infect susceptible people (that is, a lowered prevalence), the heightened individual risk of tuberculosis infection due to smoking still produces a net increase in tuberculosis incidence (fig 2).

The model projected that smoking would delay the achievement of the millennium development goal mortality target by at least 20 years in all WHO regions; smoking would also render the target unreachable in the western Pacific (table $2 \Downarrow$ ). Current WHO projections for achieving the millennium development goals were estimated by methods that ignored smoking; when we excluded the effects of smoking in our model, it estimated achievement dates within five years of WHO projections (table 2). ${ }^{30} 41$

\section{Pessimistic scenario}

If smoking prevalence increased at twice the current rate to a maximum of $50 \%$ prevalence, 290 million cumulative cases of tuberculosis and 114 million cumulative deaths from

tuberculosis would be expected between 2010 and 2050 - that is, an increase of $6 \%$ and $12 \%$, respectively, above the baseline scenario. The model also projected an increase in the number of smoking attributable tuberculosis cases (from 18 million (standard error 16 to 20 ) to 34 million (29 to 39)) and smoking attributable deaths from tuberculosis (from 40 million (39 to $41)$ to 114 million (113 to 115$)$ ) (web appendix). The model estimated that achievement of the millennium development goal mortality target would be delayed by at least 35 years in the pessimistic scenario.

\section{Optimistic scenario}

If tobacco control efforts reduced smoking prevalence by $1 \%$ per year in each WHO region from 2015 and eventually eliminated smoking, 239 million cumulative tuberculosis cases and 74 million cumulative deaths from tuberculosis would be expected between 2010 and 2050 - that is, a reduction of $13 \%$ and $27 \%$, respectively, from the baseline scenario. The model projected aggressive tobacco control to avert 18 million tuberculosis cases (standard error 14 to 22) and reduce the number of smoking attributable deaths from tuberculosis from 40 million (39 to 41 ) to 13 million (12 to 14 ). The model also projected that aggressive tobacco control would shorten the time to achieve the mortality millennium development goal ( $>15$ years, optimistic scenario $v>20$ years, baseline scenario).

\section{Passive smoking and HIV-smoking synergy}

The model projected that passive smoking would increase the cumulative number of tuberculosis cases and deaths between 2010 and 2050 by $35 \%$ and $167 \%$, respectively, higher than the baseline scenario, to 369 million tuberculosis cases and 149 million deaths from tuberculosis, respectively (incorporating both active and passive smoking). Therefore, a total of 113 million tuberculosis cases (standard error 92 to 134) and 88 million deaths from tuberculosis ( 86 to 90 ) would be attributable to smoking between 2010 and 2050. The model estimated that passive and active smoking would delay achievement of the millennium development goal mortality target by more than 26 years (compared with a delay of more than 20 years in the baseline scenario incorporating only active smoking).

We expected the potential synergy of HIV and smoking to have limited effect on mortality. In this model, an increase in non-tuberculosis mortality among HIV infected smokers led to death from other diseases before people developed active tuberculosis. Although the total number of tuberculosis cases fell to 271 million (with 14 million smoking attributable cases (standard error 12 to 16), 1\% lower than the baseline scenario), the total number of deaths from tuberculosis remained at 101 million (40 million smoking attributable deaths (39 to 41), similar to the baseline scenario).

\section{Discussion \\ Principal findings}

Smoking has not, traditionally, been incorporated into mathematical models of tuberculosis, because risk factors with a very high impact at the individual level on tuberculosis prognosis have typically been the focus of such models. ${ }^{42}$ Although the relative risk of tuberculosis from smoking is lower at an individual level than from risk factors such as HIV ${ }^{43}$ our model shows that the greater number of smokers worldwide can produce a large population attributable risk for tuberculosis. Tobacco smoking could substantially increase tuberculosis cases and deaths worldwide by 2050 , and potentially delay major goals to control tuberculosis mortality by at least 20 years if current smoking trends continue. Aggressive tobacco control measures could avert millions of deaths from tuberculosis over the next four decades if these predictions are correct.

According to our model, the African, eastern Mediterranean, and South East Asian WHO regions would be expected to have the greatest increase in new tuberculosis cases attributable to smoking (African rates would rise owing to the high risk of 
tuberculosis infection, despite a low smoking prevalence). Our estimates also included new tuberculosis infections among smokers and secondary infections among non-smokers, which predicted tuberculosis cases would increase by $7 \%$ and deaths by $66 \%$, compared with model predictions that do not account for the effect of smoking. If smoking trends were to increase worldwide in accordance with ongoing tobacco industry efforts, ${ }^{9}$ the model predicted cases and deaths from tuberculosis to increase beyond levels based on existing smoking trends, with the highest burdens in Africa, the eastern Mediterranean, South East Asia, and the western Pacific.

Aggressively lowering the prevalence of tobacco smoking could reduce smoking attributable deaths from tuberculosis by 27 million by 2050 , under the optimistic setting of a $1 \%$ reduction in smoking rate per year (seen in some US states with successful tobacco control) to the point of eradication. The greatest tuberculosis related benefits from tobacco control were expected in Europe, the western Pacific, and South East Asia. Our model also accounted for smoking attributable deaths not related to tuberculosis (for example, lung cancer), hence the effect of tobacco on mortality was the added tuberculosis impact beyond that expected from other smoking related deaths.

\section{Strengths and weaknesses of study}

As with all mathematical models, our results are limited by the modelling assumptions made. We modelled the effects of smoking on tuberculosis infection and mortality in accordance with published data, principally a meta-analysis of 33 studies (web appendix). If effect sizes are small, the effect of confounding third variables could be substantial; to keep this effect to a minimum, we used relative risks derived from a stratified analysis correcting for the impact of alcohol and socioeconomic status. Smoking also produces pulmonary lesions, which themselves could confound tuberculosis diagnosis by chest radiograph, leading to overdiagnosis among smokers. Therefore, we based our risk estimates on studies with independent confirmation of tuberculosis (for example, autopsy). Nevertheless, studies of the impact of smoking on tuberculosis tend to oversample clinic patients to derive control groups, potentially underestimating the relative impact of tobacco and generating low estimates of tobacco impact from our model.

Another source of uncertainty concerns our projections of future trends in tuberculosis control and smoking. We estimated case detection and treatment success rates by regressing curves against data from expert panels and statistical extrapolations. ${ }^{41}$ This procedure might overestimate the impact of ongoing treatment efforts on tuberculosis control. ${ }^{41} \mathrm{We}$ also lacked longitudinal data on annual smoking prevalence in each WHO region and had to estimate smoking prevalence from tobacco demand data. Because tobacco companies are using less tobacco per cigarette than in previous years and sales of informal cigarettes are not always reported (such as bidis, which are thought to deliver higher smoke content than normal cigarettes),${ }^{44}$ the same tobacco demand could indicate a rise in the actual number of smokers, causing our method to underestimate the risk of tuberculosis.

\section{Strengths and weaknesses in relation to other studies}

Because smoking has had such a profound impact on tuberculosis mortality in this model, it has rendered some traditional tuberculosis outcome variables potentially unreliable. Population attributable risk is commonly used to calculate the impact of a risk factor on disease rates, but does not account for the secondary cases produced by each primary infectious disease case. Tuberculosis prevalence is also used to assess the success of tuberculosis control efforts by international bodies and national health ministries. ${ }^{30}$ But when a cofactor such as smoking increases both the risk of primary infection and the risk of mortality, it remains unclear how prevalence will change, because the mortality increase could partly or completely outweigh the increase in incidence (Little's law).$^{45}$ The model presented here shows that point prevalence could fall because of smoking's heavy impact on mortality, even while tuberculosis incidence remains increased, producing a false sense of reassurance if we use prevalence statistics as a gauge of tuberculosis programme efficacy. A dynamic mathematical model such as ours captures these complex time dependent trends in tuberculosis better than linear extrapolation techniques typically used to estimate the impact of smoking.

\section{Implications of study findings}

The passage of the WHO Framework Convention on Tobacco Control and its ratification by 174 countries (as of July 2011) provides new opportunities to reduce smoking. ${ }^{46}$ Less than $10 \%$ of the world's population, however, is currently covered by effective tobacco control programmes and although all the treaty parties must regularly report on progress, the reporting system is imperfect and not fully enforced. ${ }^{47}$

According to the model described here, tobacco smoking substantially increases tuberculosis cases and deaths worldwide and might delay the achievement of tuberculosis mortality goals. Tuberculosis control efforts still rely heavily on treatment based control, with tobacco cessation infrastructure being minimally integrated into control programmes. In the past, multinational tobacco companies have attempted to persuade health organisations to focus on infectious diseases rather than tobacco control. ${ }^{48}$ Our results show that this is a false dichotomy: tobacco control is tuberculosis control.

\section{Unanswered questions and future research}

We had insufficient information to incorporate a dose response association between the duration of smoking or degree of smoke exposure (for example, years of smoking or cigarettes per day) and tuberculosis risk, alternative tobacco products, or other smoke effects (for example, use of hookahs or indoor air pollution); sex specific aspects of tuberculosis pathogenesis (for example, potential sex differences in pathogenesis, which could synergise with smoking's increased prevalence in men); or the potential implications of smoking on treatment adherence and resistance to tuberculosis drugs. We followed traditional tuberculosis models by simulating people older than 15 years, since they account for the majority of transmission, and parameters used to describe childhood tuberculosis remain poorly understood. ${ }^{25}$

Effects of passive smoking and interactions between HIV and smoking also remain uncertain because of limited data from which to base model parameters. Passive smoking in particular could greatly amplify the number of tuberculosis cases attributable to smoking. Few studies have reviewed the effect of passive smoking on tuberculosis, and the subject merits further investigation.

Finally, as efforts are underway to propose new targets after the 2015 deadline for the millennium development goals, new goals and prospects for tuberculosis control should consider the need to model host susceptibility factors such as tobacco when accounting for the potential success or failure of, on one hand, tobacco industry efforts to expand markets in developing 
countries where tuberculosis is common, and, on the other hand, tobacco control programmes. Smoking targets can also assist with targets in tuberculosis control. Small scale studies of the impact of smoking cessation on tuberculosis outcomes have suggested substantial benefits from tobacco cessation, but data are preliminary. ${ }^{49}$

This article was prepared with the use of limited access data from the World Health Organization and United Nations Programme on HIV/AIDS, and does not necessarily reflect the opinions or views of these organisations. We thank Douglas Bettcher for his insights and assistance.

Contributors: SB and SAG prepared the model and analysed the results; $D S$ and $A B$ participated in the presentation and interpretation of results. All authors contributed to the drafting of the manuscript. SB is guarantor of the article.

Funding: SB is supported partly by the US Centers for Disease Control and Prevention (R36-Cl000607-01) and the National Institutes of Health (T32-GM07205-32). The sponsors had no role in study design, data collection, data analysis, data interpretation, or writing of the report. The corresponding author had full access to all the data in the study, and all authors had final responsibility for the decision to submit for publication.

Conflicts of interest: All authors have completed the Unified Competing Interest form at http://www.icmje.org/coi_disclosure.pdf (available on request from the corresponding author) and declare: SB is supported partly by the US Centers for Disease Control and Prevention (R36-Cl000607-01) and the National Institutes of Health (T32-GM07205-32); no financial relationships with any organisations that might have an interest in the submitted work in the previous three years, no other relationships or activities that could appear to have influenced the submitted work.

Ethical approval: Ethical approval was not required for this work. Data sharing: No additional data available.

1 Stop TB Partnership. The global plan to stop TB 2006-2015. World Health Organization, 2006

2 World Health Organization. The stop TB strategy-building on and enhancing DOTS to meet the TB-related Millennium Development Goals. WHO, 2006.

3 Lonnroth K, Jaramillo E, Williams BG, Dye C, Raviglione M. Drivers of tuberculosis epidemics: the role of risk factors and social determinants. Soc Sci Med 2009;68:2240-6.

4 Dye C, Lonnroth K, Jaramillo E, Williams BG, Raviglione M. Trends in tuberculosis incidence and their determinants in 134 countries. Bull World Health Organ 2009;87:683-91.

5 World Health Organization. Global tuberculosis control-surveillance, planning, financing. World Health Organization, 2008

6 Esson K. The Millennium development goals and tobacco control: an opportunity for global partnership. World Health Organization, 2004.

7 Muggli ME, Hurt RD. Listening between the lines: what BAT really thinks of its consumers in the developing world. Tob Control 2003;12:104.

8 Otanez MG, Mamudu HM, Glantz SA. Tobacco companies' use of developing countries economic reliance on tobacco to lobby against global tobacco control: the case of Malawi. Am J Public Health 2009;99:1759-71.

9 Wilson D. Cigarette giants in global fight on tighter rules. New York Times, 2010

10 Lin HH, Ezzati M, Murray M. Tobacco smoke, indoor air pollution and tuberculosis: a systematic review and meta-analysis. PLoS Med 2007;4:e20.

11 Dye C, Williams BG. Criteria for the control of drug-resistant tuberculosis. Proc Nat/ Acad Sci U S A 2000;97:8180-5.

12 Dye C, Garnett GP, Sleeman K, Williams BG. Prospects for worldwide tuberculosis control under the WHO DOTS strategy. Directly observed short-course therapy. Lancet 1998;352:1886-91

13 United Nations Population Division. World population prospects. United Nations, 2008.

14 Williams BG, Dye C. Antiretroviral drugs for tuberculosis control in the era of HIV/AIDS. Science 2003;301:1535-7.

15 Doll R, Peto R, Boreham J, Sutherland I. Mortality in relation to smoking: 50 years observations on male British doctors. BMJ 2004:328:1519.

16 World Health Organization. WHO Global Health Observatory (GHO). WHO, 2010.
17 Corbett EL, Bandason T, Cheung YB, Munyati S, Godfrey-Faussett P, Hayes RJ, et al. Epidemiology of tuberculosis in a high HIV prevalence population provided with enhanced diagnosis of symptomatic disease. PLoS Med 2007;4:e22.

18 Jha P, Jacob B, Gajalakshmi V, Gupta PC, Dhingra N, Kumar R, et al. A nationally representative case-control study of smoking and death in India. N Engl J Med 2008;358:1137-47.

19 John RM, Sung HY, Max W. Economic cost of tobacco use in India, 2004. Tob Control 2009;18:138-43.

20 Rockhill B, Newman B, Weinberg C. Use and misuse of population attributable fractions. Am J Public Health 1998;88:15-9.

21 Anderson RM, May RM. Infectious diseases of humans: dynamics and control . Oxford University Press, 1991.

22 Basu S, Maru D, Poolman E, Galvani A. Primary and secondary tuberculosis preventive treatment in HIV clinics: simulating alternative strategies. Int $J$ Tuberc Lung Dis 2009;13:652-8.

23 Basu S, Friedland GH, Medlock J, Andrews JR, Shah NS, Gandhi NR, et al. Averting epidemics of extensively drug-resistant tuberculosis. Proc Natl Acad Sci U S A 2009;106:7672-7.

24 Dowdy DW, Chaisson RE, Maartens G, Corbett EL, Dorman SE. Impact of enhanced tuberculosis diagnosis in South Africa: a mathematical model of expanded culture and drug susceptibility testing. Proc Natl Acad Sci U S A 2008;105:11293-8.

25 Basu S, Andrews JR, Poolman EM, Gandhi NR, Shah NS, Moll A, et al. Prevention of nosocomial transmission of extensively drug-resistant tuberculosis in rural South African district hospitals: an epidemiological modelling study. Lancet 2007;370:1500-7.

26 Dye $\mathrm{C}$, Williams BG. Eliminating human tuberculosis in the twenty-first century. $J$ R Soc Interface 2008;5:653-62.

27 Akaike $\mathrm{H}$. A new look at the statistical model identification. IEEE Transactions on Automatic Control 1974;19:716-23.

28 Bolker BM. Ecological models and data in R. Princeton University Press, 2008.

29 World Health Organization. Global TB database. WHO, 2010.

30 World Health Organization. Global tuberculosis control 2010. WHO, 2010.

31 UNAIDS. AIDS epidemic update 2009. UNAIDS, 2010

32 Food and Agriculture Organization of the United Nations. Projections of tobacco production, consumption and trade. United Nations, 2010.

33 World Health Organization. WHO report on the global tobacco epidemic, 2009: implementing smoke-free environments. WHO, 2009.

34 Wen CP, Chan TC, Chan HT, Tsai MK, Cheng TY, Tsai SP. The reduction of tuberculosis risks by smoking cessation. BMC Infect Dis 2010;10:156.

35 American Cancer Society. The tobacco atlas. ACS, 2009.

36 Lightwood JM, Dinno A, Glantz SA. Effect of the California tobacco control program on personal health care expenditures. PLOS Med 2008;5:e178.

37 One News. Govt commits to smokefree NZ by 2025. Television New Zealand Limited 2011.

38 World Health Organization. A WHO/The Union monograph on TB and tobacco control. WHO, 2005.

39 Crothers K, Goulet JL, Rodriguez-Barradas MC, Gibert CL, Oursler KA, Goetz MB, et al. Impact of cigarette smoking on mortality in HIV-positive and HIV-negative veterans. AIDS Educ Prev 2009;21(suppl 3):40-53.

40 Nieman RB, Fleming J, Coker RJ, Harris JR, Mitchell DM. The effect of cigarette smoking on the development of AIDS in HIV-1-seropositive individuals. AIDS 1993;7:705-10.

41 Dye C, Watt CJ, Bleed DM, Hosseini SM, Raviglione MC. Evolution of tuberculosis contro and prospects for reducing tuberculosis incidence, prevalence, and deaths globally. JAMA 2005;293:2767-75

42 Williams BG, Granich R, Chauhan LS, Dharmshaktu NS, Dye C. The impact of HIV/AIDS on the control of tuberculosis in India. Proc Natl Acad Sci U S A 2005;102:9619-24.

43 Broek JBM, Pakker NG, Newell JN, Senkoro KP, Klokke AH. Risk of HIV infection for developing active tuberculosis. Int Conf AIDS 1992:8:C314.

44 Pakhale SS, Maru GB. Distribution of major and minor alkaloids in tobacco, mainstream and sidestream smoke of popular Indian smoking products. Food Chem Toxicol 1998;36:1131-8.

45 Leon-Garcia A. Probability, statistics, and random processes for electrical engineering . Prentice Hall, 2008.

46 Taylor AL, Bettcher DW. WHO framework convention on tobacco control: a global "good" for public health. Bull World Health Organ 2000;78:920-9.

47 Bitton A, Raw M, Richards A, McNeill A, Rigotti NA. A comparison of four internationa surveys of tobacco dependence treatment provision: implications for monitoring the framework convention on tobacco control. Addiction 2010;105:2184-91.

48 Zeltner T, Kessler DA, Martiny A, Randera F. Tobacco company strategies to undermine tobacco control activities at the World Health Organization: report of the Committee of Experts on Tobacco Industry Documents. WHO, 2000.

49 El Sony A, Slama K, Salieh M, Elhaj H, Adam K, Hassan A, et al. Feasibility of brie tobacco cessation advice for tuberculosis patients: a study from Sudan. Int J Tuberc Lung Dis 2007;11:150-5.

Accepted: 28 July 2011

\section{Cite this as: BMJ 2011;343:d5506}

This is an open-access article distributed under the terms of the Creative Commons Attribution Non-commercial License, which permits use, distribution, and reproduction in any medium, provided the original work is properly cited, the use is non commercial and is otherwise in compliance with the license. See: http://creativecommons.org/licenses/by$\mathrm{nc} / 2.0 /$ and http://creativecommons.org/licenses/by-nc/2.0/legalcode. 


\section{What is already known on this topic}

Smoking has been linked to increased individual risk of tuberculosis infection and mortality, but its impact on future population rates of tuberculosis is unclear

We developed a mathematical model to estimate how future smoking trends can affect tuberculosis control

\section{What this study adds}

The model predicted that smoking could produce an excess of 18 million tuberculosis cases and 40 million deaths from tuberculosis worldwide, between 2010 and 2050

Smoking is expected to delay achievement of the millennium development goal in tuberculosis mortality control Aggressive tobacco control could avert 27 million deaths from tuberculosis attributable to smoking by 2050

\section{Tables}

\begin{tabular}{|c|c|c|c|c|c|}
\hline \multicolumn{6}{|l|}{ Table 1 | Values of model parameters } \\
\hline Model parameter and definition (unit) & $\begin{array}{l}\text { HIV negative mean of } \\
\log (S D)\end{array}$ & $\begin{array}{l}\text { HIV positive mean of log } \\
\text { (SD) }\end{array}$ & $\begin{array}{l}\text { HIV negative } \\
\text { geometric mean }\end{array}$ & $\begin{array}{l}\text { HIV positive } \\
\text { geometric mean }\end{array}$ & Reference \\
\hline $\begin{array}{l}\text { c: close contact and transmission rate } \\
\text { (person/year) }\end{array}$ & $2.26(0.12)$ & $2.26(0.12)$ & 9.73 & 9.73 & 11 \\
\hline $\begin{array}{l}f: \text { active tuberculosis cases that are infectious } \\
\text { (proportion) }\end{array}$ & $-0.51(0.05)$ & $-1.23(0.15)$ & 0.60 & 0.29 & 12 \\
\hline$b$ : birth rate (per year) & Varied ${ }^{*}$ & Varied ${ }^{*}$ & $\mathrm{~N} / \mathrm{a}$ & $\mathrm{N} / \mathrm{a}$ & 13 \\
\hline $\begin{array}{l}\mu \text { : background (non-tuberculosis) mortality rate } \\
\text { in non-smokers (per year) }\end{array}$ & $-3.89(0.27)$ & $-2.32(0.02)$ & 0.02 & 0.10 & 12,14 \\
\hline $\begin{array}{l}\mu_{\mathrm{s}}: \text { background (non-tuberculosis) mortality rate } \\
\text { in smokers (per year) }\end{array}$ & $-3.62(0.39)$ & $-2.27(0.02)$ & 0.03 & 0.10 & 15 \\
\hline$\mu_{\mathrm{T}}:$ mortality rate due to tuberculosis (per year) & $-1.21(0.14)$ & $-0.08(0.06)$ & 0.30 & 0.91 & 11,12 \\
\hline $\begin{array}{l}p \text { : newly infected individuals with primary } \\
\text { progressive disease (proportion) }\end{array}$ & $-1.92(0.24)$ & $-0.54(0.15)$ & 0.15 & 0.60 & 12 \\
\hline $\begin{array}{l}\delta: \text { active tuberculosis cases detected } \\
\text { (proportion) }\end{array}$ & Varied $\dagger$ & Varied $\dagger$ & $\mathrm{N} / \mathrm{a}$ & $\mathrm{N} / \mathrm{a}$ & 16 \\
\hline$\varepsilon:$ detection and treatment rate (per year) & $-0.20(0.40)$ & $0.46(0.29)$ & 0.62 & 2.89 & 17 \\
\hline $\begin{array}{l}\text { к: detected cases that are successfully treated } \\
\text { (proportion) }\end{array}$ & Varied $\ddagger$ & Varied $\neq$ & $\mathrm{N} / \mathrm{a}$ & $\mathrm{N} / \mathrm{a}$ & 16 \\
\hline$\sigma:$ rate of natural self-cure (per year) & $-1.61(0.11)$ & $-2.54(0.46)$ & 0.20 & 0.08 & 12 \\
\hline $\begin{array}{l}\text { v: reactivation rate of latency to active } \\
\text { tuberculosis (per year) }\end{array}$ & $-8.68(0.27)$ & $-1.98(0.26)$ & $1.66 \times 10^{-4}$ & 0.13 & 12 \\
\hline $\begin{array}{l}\mathrm{X} \text { : reinfected individuals who undergo primary } \\
\text { progression (proportion) }\end{array}$ & $-1.09(0.30)$ & $-0.33(0.14)$ & 0.33 & 0.74 & 12 \\
\hline 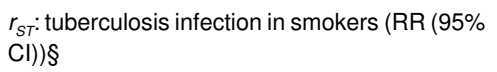 & 2.0 (1.5 to 2.6$)$ & 2.0 (1.5 to 2.6$)$ & $\mathrm{N} / \mathrm{a}$ & $\mathrm{N} / \mathrm{a}$ & 10 \\
\hline $\begin{array}{l}r_{S 0} \text { : tuberculosis mortality in smokers (RR }(95 \% \\
\mathrm{Cl}) \S\end{array}$ & 2.6 (1.8 to 3.6$)$ & 2.6 (1.8 to 3.6$)$ & $\mathrm{N} / \mathrm{a}$ & $\mathrm{N} / \mathrm{a}$ & 10 \\
\hline
\end{tabular}

$\mathrm{RR}=$ relative risk. $95 \% \mathrm{Cl}=95 \%$ confidence intervals. Variables sampled from log-normal distributions. Geometric means given for reference. Web appendix provides details on incorporation of HIV, case detection, and treatment success rates. *Varied by year; see reference.

†Varied by location and year; see text.

$\ddagger$ Varied by location and year; see web appendix.

§See table 3 in web appendix for primary data. 


\begin{tabular}{|c|c|c|c|c|c|c|}
\hline \multirow[b]{3}{*}{ Region } & \multicolumn{3}{|c|}{ Tuberculosis prevalence } & \multicolumn{3}{|c|}{ Tuberculosis mortality } \\
\hline & \multirow{2}{*}{$\begin{array}{c}\text { Goal rate (per } \\
100000)\end{array}$} & \multicolumn{2}{|c|}{ Estimated year of achievement } & \multirow{2}{*}{$\begin{array}{l}\text { Goal rate (per } \\
100000)\end{array}$} & \multicolumn{2}{|c|}{ Estimated year of achievement } \\
\hline & & Without smoking & With smoking & & Without smoking & With smoking \\
\hline Africa & 137 & Never* $^{*}$ & Never $^{*}$ & 16 & Never* & Never* \\
\hline Americas & 49 & 2000 & $1999 \dagger$ & 4 & $2006 \ddagger$ & $2029 \ddagger$ \\
\hline $\begin{array}{l}\text { Eastern } \\
\text { Mediterranean }\end{array}$ & 132 & 2019 & 2020 & 17 & $2014 \ddagger$ & $2062 \ddagger$ \\
\hline Europe & 48 & 2030 & $2027 \dagger$ & 6 & 2024 & 2048 \\
\hline South East Asia & 188 & 2009 & $2008 \dagger$ & 24 & $2007 \ddagger$ & $2033 \ddagger$ \\
\hline Western Pacific & 150 & 2013 & $2001 \dagger$ & 17 & $2009 \ddagger$ & Never ${ }^{*} \ddagger$ \\
\hline
\end{tabular}

Table 2 Effect of smoking on achievement of millennium development goal target to control tuberculosis prevalence and mortality

Years estimated with standard error of 3 years on each side. Mortality excludes HIV-tuberculosis cases (unlike fig 3), to accord with data in WHO report on millennium development goal tuberculosis targets and current tuberculosis mortality estimates.

*Steady state rate is higher than target rate.

†Mortality from smoking can cause point prevalence to fall; hence prevalence target can be achieved earlier in the smoking model. This reduction reflects a rise in deaths attributable to smoking rather than improved tuberculosis control.

$\ddagger \mathrm{WHO}$ regions that will miss millennium development goal target to control tuberculosis mortality because of smoking. 


\section{Figures}

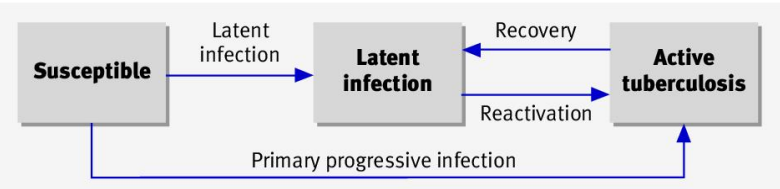

Fig 1 Mathematical model of tuberculosis infection, pathogenesis, and mortality. Model calculates the population prevalence of smoking and of HIV in each year of the simulation, and then calculates how the number of new tuberculosis cases and deaths are affected by the increased risk of infection or death posed by each risk factor. Model also incorporates rates of reinfection, case detection, and treatment success, as well as non-tuberculosis mortality, and tuberculosis mortality (web appendix) 

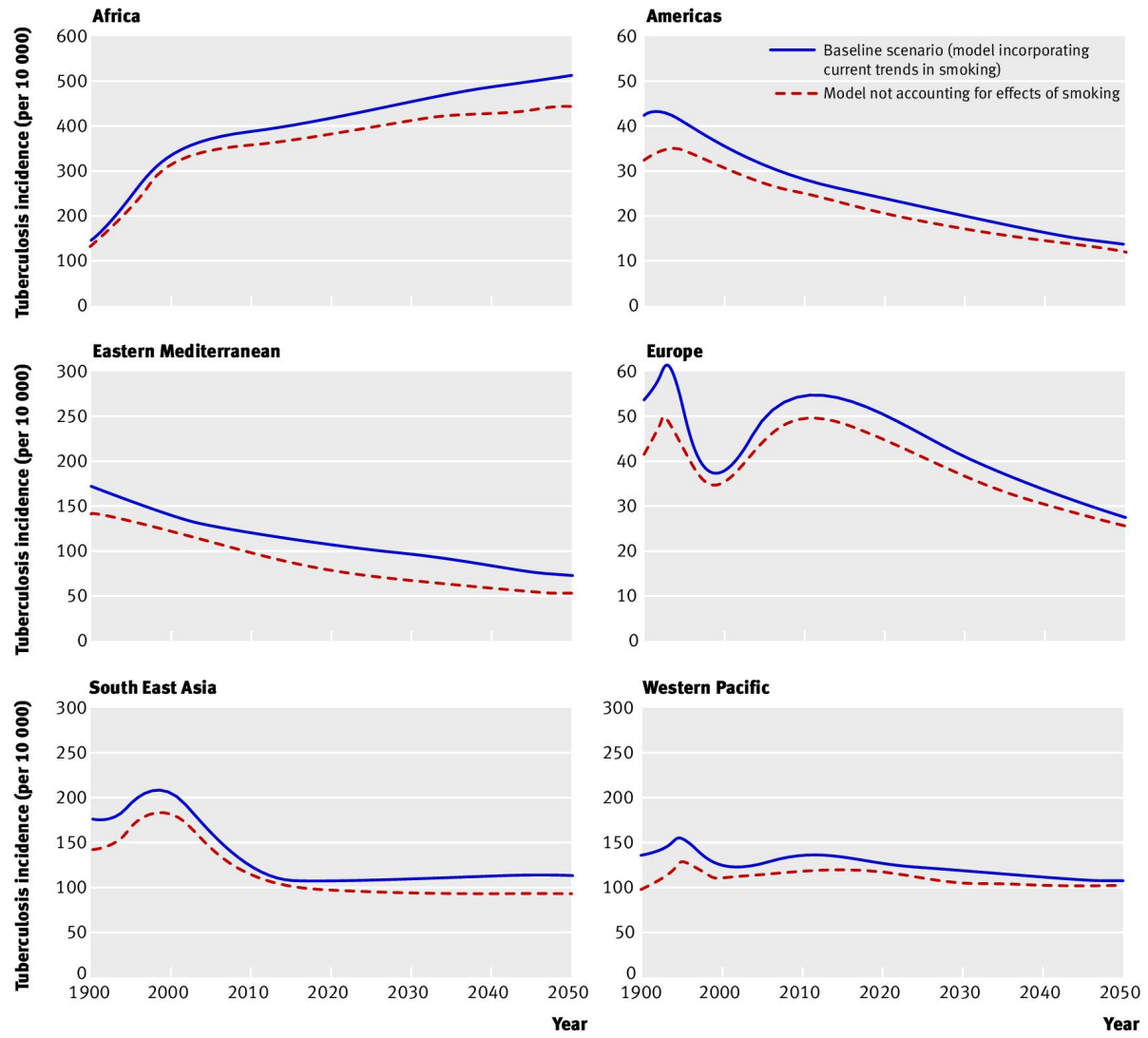

Fig 2 Effect of smoking on tuberculosis incidence in WHO regions 

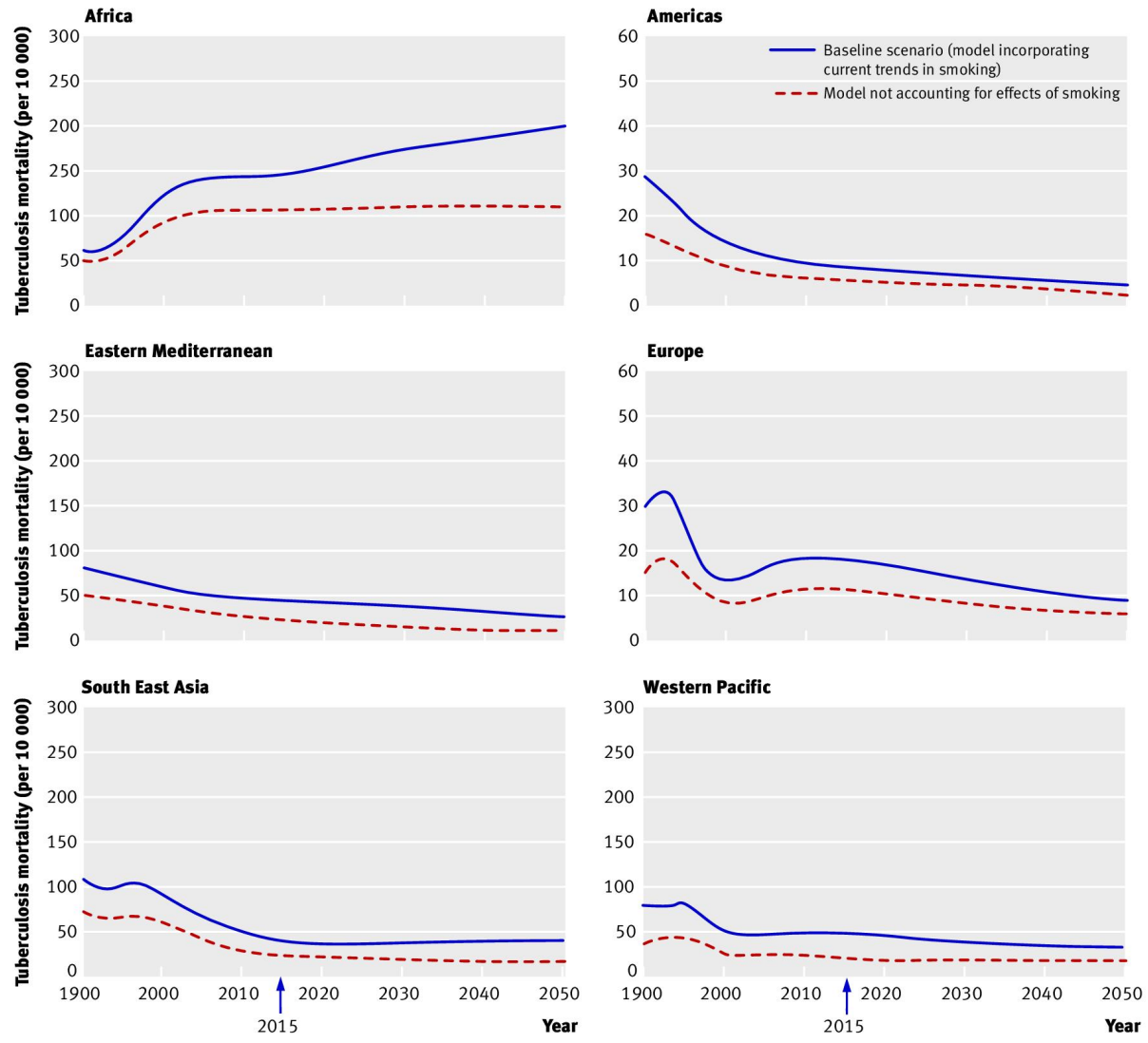

Fig 3 Effect of smoking on tuberculosis mortality in WHO regions. Arrow=millennium development goal to reduce tuberculosis mortality and prevalence by half by 2015 

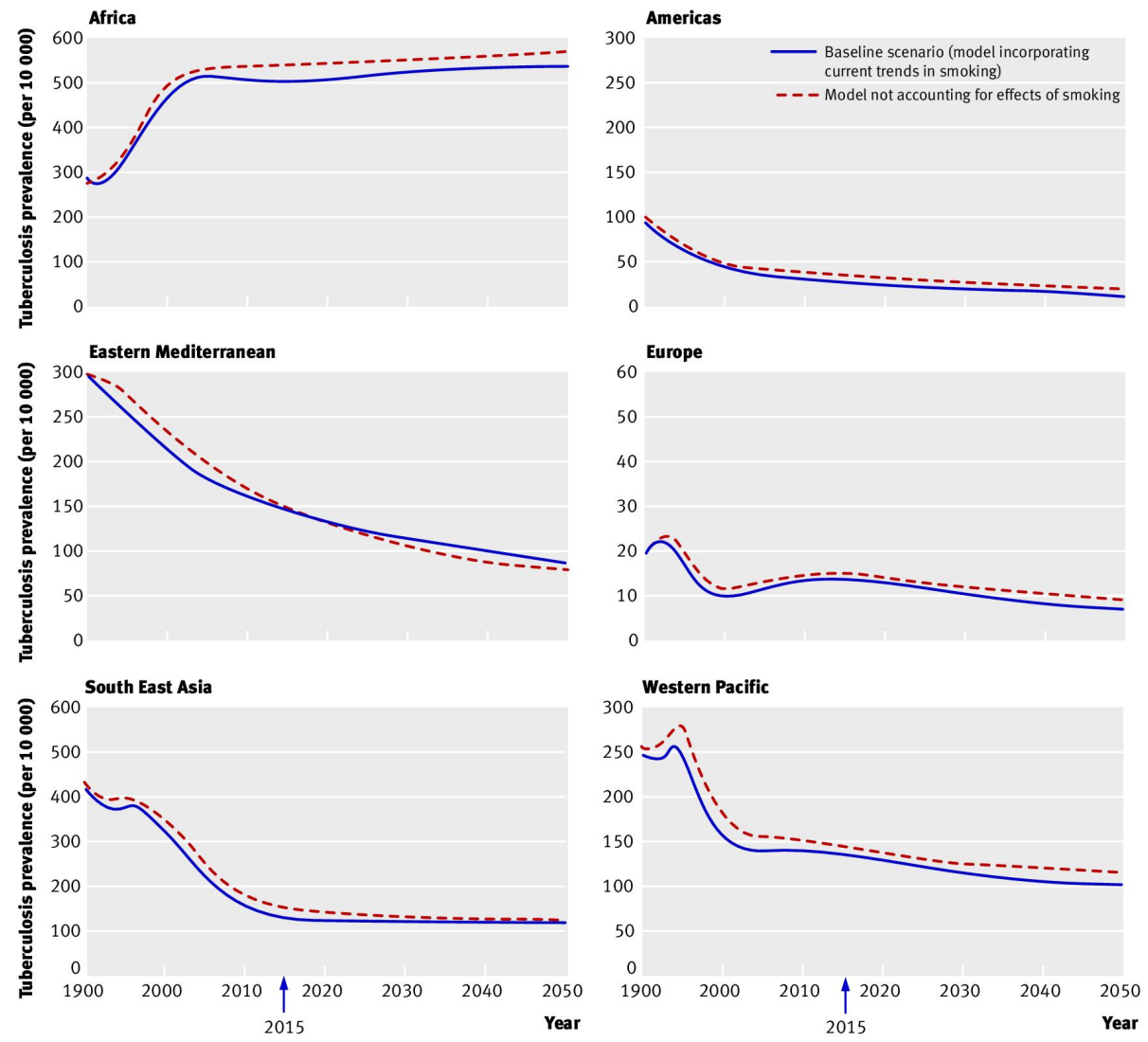

Fig 4 Effect of smoking on tuberculosis prevalence statistics. Arrow=millennium development goal to reduce tuberculosis mortality and prevalence by half by 2015 